\title{
Reproducción de piezas arqueológicas
}

Harold Krusell

La necesidad de réplicas exactas, por razón de preservar los originales para el trabajo científico y usar en su lugar reproducciones ya sea para muestras museográficas, intercambio de material arqueológico o con propósitos docentes ha motivado el desarrollo de técnicas especializadas que apoyan la actividad científica en este aspecto.

Las técnicas de moldaje y vaciado, conservando la máxima fidelidad en cuanto a forma, color y texturas son fundamentalmente artesanales y revisten algunas particularidades en cuanto a método y materiales.

El interés que presenta para el artista esta actividad estrictamente técnica es que además de proporcionarle la oportunidad de manipular (manosear) y observar muy directamente, algunas veces, material de gran valor artístico, le exige un desarrollo del oficio riguroso que luego podrá aplicar a sus trabajos de creación, con dominio y soltura.

La técnica de la reproducción de piezas tiene dos fases: la primera es el moldaje y, la segunda, el vaciado.

Para que una pieza salga perfecta, el molde ha de ser perfecto.

No existen normas estrictas para hacer un buen molde. Cada caso presenta problemas propios, y esos podrán ser solucionados de diversas maneras. Lo dicho vale también para el vaciado.

Lo fundamental es conocer la naturaleza de la pieza original y asegurarse de que el material que se use y el procedimiento no dañará el modelo.

\section{Naturaleza del original}

Las piezas arqueológicas objeto de reproducciones, por lo general, se reducen a los siguientes materiales:
a) piedra
b) cerámica
c) madera
d) huesos
e) metal

El material lítico no presenta mayores problemas por su consistencia física y estabilidad química, no afectándole los materiales de moldaje ni el procedimiento, a excepción de una piedra que fuera demasiado porosa, la que pudiera absorber parte del agua del material de moldeo antes de fraguar y ofrecer mucha traba mecánica. Para obviar estas dificultades debe tratarse el original con un desmoldante impermeabilizante, o empapar previamente la pieza. Normalmente las piedras usadas para herramientas líticas son basaltos (andesita-dasita), sílice o sílex (riolita, cuarzo y sus variantes), obsidiana y lajas, las cuales son compactas y duras y no presentan problemas de absorción de agua. Cuando se usa material de moldaje flexible, se obtiene con cualquiera de ellos la máxima fidelidad, no requiriendo desmoldante.

El material cerámico presenta, en general, características buenas para su moldeo, ya que resiste el agua y la temperatura, siendo su superficie bastante lisa y regular, excepto algunos casos como la cerámica muy primitiva y la corriente. Es perfectamente moldeable en yeso y materiales elásticos, previa aplicación de desmoldante para facilitar la salida del molde.

Las piezas de madera pueden representar distintos estados de conservación. Desde una buena consistencia propia de la madera sana con una superficie pulida, hasta un estado avanzado de descomposición en que la resistencia es nula y la superficie muy porosa y áspera que produce problemas para su moldeo a incluso para su manipulación, no resistiendo el procedimiento. Moldear material en este estado es destruirlo. Lo que procede es revestirlo con un barniz para su conservación. En algún caso pudiera necesitarse un molde sacrificando el original, cuando su pérdida es inminente.

Al moldear una pieza de madera debe tenerse en cuenta su capacidad de absorción de agua con el 
correspondiente hinchamiento. Por lo que debe protejerse con un desmoldante impermeabilizante, o moldearse con material gomoelástico asegurando aislarlo para evitar la adherencia.

El material óseo presenta características similares a las de la madera, por su estado de conservación, porosidad y adherencia a los materiales de moldeo.

Los metales, en general, no presentan problemas excepto por sus pátinas, las que se ven disminuidas al moldear.

\section{Materiales de moldaje}

Un material apto para moldaje es aquel que en su estado líquido o pastoso puede tomar impresiones con nitidez y que luego, al endurecer y retirarse del modelo, éstas no se pierdan o disminuyan notoriamente. Se pueden clasificar en material de moldaje rígido y material de moldaje flexible. Este último es el que luego de endurecer por enfriamiento o fraguado se deforma elásticamente al tropezar con un obstáculo, retención o ángulo muerto y luego recupera su posición original.

Entre los materiales de moldaje rígido el más importante es el yeso en sus variedades de yeso corriente y yeso piedra, siendo este último el más indicado para moldaje de piezas que se van a reproducir más de una vez. La fidelidad del yeso se debe en gran parte a su fluidez en estado líquido y a la expansión que experimenta durante el fraguado. Esta expansión puede ser peligrosa para el modelo, si las formas son interiores.

Para lograr una máxima fidelidad es conveniente recubrir el original con una finísima capa de agua, la que servirá de vehículo para que el yeso penetre los más finos detalles.

La reacción de fraguado es exotérmica, siendo más notorio el aumento de temperatura cuanto mayor sea la masa de yeso, y es acompañada por una exudación producto de la evaporación de un porcentaje del agua usada en la preparación. Esta humedad puede ser absorbida por el modelo.

El yeso normalmente no adhiere a la madera, en cambio se afirma bastante a las piedras, huesos y a la cerámica.
Es el material que está presente en casi todos los moldes, ya sea como material de impresión o como cama del molde flexible.

Otro material rígido apto para moldaje son las resinas duras de uso general. Si bien estas presentan más consistencia una vez endurecidas, su fidelidad es menor debido a la contracción de fraguado, que es del orden de un $8 \%$, disminuyendo este porcentaje de acuerdo al refuerzo de fibra de vidrio y a la carga inerte que se le ponga. Las resinas que más se prestan para este uso son algunos polyesteres y ciertas variedades de resinas epoxídicas. A estos materiales puede dárseles cierto grado de flexibilidad de acuerdo a la proporción de polímeros elásticos que se le agreguen.

Su uso como material de moldaje se presta en especial para piezas simples de tamaño grande.

Entre los materiales elásticos para moldaje podemos distinguir: a) los hidrocoloides, reversibles e irreversibles. Entre estos últimos interesan especialmente los Alginatos ya que presentan mayor estabilidad dimensional por efecto de imbibición o exudado, y fácil manejo. Tiene sí el inconveniente de no resistir muchos vaciados ni almacenaje prolongado del molde. Es especialmente indicado para trabajos pequeños rápidos con pocas copias. Se usa sobre cama de yeso. Está formado por geles hidrocoloidales (hidrófilo) y su reacción de fraguado se considera como la de los polímeros; b) Los elastómeros son materiales compuestos por geles coloidales hidrófobos. Los hay termoplásticos (reversibles) y termocurables o irreversibles. Tanto los unos como los otros son clave para el trabajo de reproducciones, por su óptima fidelidad, elasticidad, resistencia mecánica, estabilidad dimensional y no experimentan inhibición ni exudado por efecto del agua.

Los termoplásticos son polímeros que a temperatura ambiente son sólidos y elásticos, a los que al aplicársele calor (entre 120 y $160^{\circ} \mathrm{C}$ ) se ablanda hasta quedar fluidos, y que al volverse a enfriar recuperan su estado inicial, tantas veces como se quiera, permitiendo con ello recuperar el material luego de haber sido utilizado el molde. Se pueden almacenar los moldes en este material por tiempo indefinido no variando sus propiedades de fidelidad y elasticidad. 
Los termocurables son materiales que se presentan en estado líquido-pastoso a temperatura ambiente y con su respectivo endurecedor. Al aplicársele este último se produce la reacción típica de fraguado de los polímeros siendo ésta irreversible.

Entre los termocurables tenemos una serie de cauchos de silicona vulcanizables en frío. A las propiedades anteriores, y a excepción de su recuperabilidad, se suman una mayor fidelidad, más fácil manejo y la propiedad contraria a la adhesión a toda materia orgánica, a excepción de los azúcares. El caucho silicona es el más útil de todos los materiales de moldaje y se usa en combinación con el yeso.

Su tiempo de fraguado es controlable, no variando notoriamente por diferencias de temperatura ambiente. Al igual que los termoplásticos permiten vaciar yeso, cemento, resinas termoplásticas y termocurables, arcillas, ceras para fundición y otros sin necesidad de desmoldante.

\section{Desmoldante}

Para evitar que un material se adhiera al fraguar o endurecer sobre su molde o modelo, se utiliza normalmente un desmoldante.

Estas sustancias, por lo general, al aplicarse al molde, lo recubren de una delgada película que lo aísla del material aplicado, impidiendo así la adherencia, tapando, además, los poros donde pudiera producirse la traba mecánica y protegiendo el original cuando de éste se trata.

Este recurso disminuye la fidelidad de la impresión, aumentando ésta cuanto más delgada sea la capa aplicada y cuanto más uniformemente se aplique.

Algunos materiales no presentan adherencia entre sí y no requieren desmoldantes; para otros basta un tratamiento al molde (o modelo), como en el caso del yeso y la cera caliente, que basta con mojar el primero para que la cera no se pegue. Lo mismo sucede con otros materiales sintéticos hidrófilos. Claro está que con ello se disminuye la fidelidad de la impresión.

Como desmoldante sirve una variedad de sustancias que en algunos casos pueden actuar como pegamentos; pero, ya sea porque se deja secar previamente o por ablandamiento (por humedad a otros factores) permite liberar una superficie de otra.

El desmoldante, al igual que el adhesivo, pueden presentarse en solución o emulsión permitiendo así una mejor, más uniforme y más delgada aplicación.

\section{Características deseables de un desmoldante}

1. Servir para los materiales usados.

2. Proteger el modelo o el molde.

3. No impedir el fraguado o endurecimiento del material usado.

4. No disminuir notoriamente la fidelidad de la impresión.

5. Dar fácil salida al molde (lubricando).

6. Ser de fácil aplicación con brocha o pulverizador, permitiendo aplicar película delgada y uniforme.

Algunas sustancias que sirven como desmoldantes para los materiales sintéticos (el uso de ellos depende de la naturaleza del modelo o molde y del material aplicado):

\begin{tabular}{|lll|}
\hline & GRASOS & $\begin{array}{l}\text { Estearina - Parafina sólida, Aceites puros o emulsionados, } \\
\text { ceras diluidas o emulsionadas. }\end{array}$ \\
$\begin{array}{lll}\text { MATERIALES } \\
\text { DESMOLDANTES }\end{array}$ & $\begin{array}{l}\text { GOMAS NATURALES } \\
\text { O SINTETICAS }\end{array}$ & $\begin{array}{l}\text { Diluidas en agua (secado lento). } \\
\text { SOLIDO }\end{array}$ \\
& Papel celofán \\
\hline
\end{tabular}


Existe una variedad de productos elaborados por las industrias químicas para tal efecto, siendo la emulsión de aceite de silicona uno de los mejores.

Algunas veces es conveniente usar dos o más sistemas de desmoldantes simultáneamente.

En el caso de un modelo delicado, puede aplicarse primeramente un barniz de protección.

\section{Material de vaciado}

Materiales de vaciado son aquellos que en su estado líquido o pastoso permiten llenar el molde, tomando de él hasta los más mínimos detalles y que luego al endurecer por enfriamiento o fraguado se pueden retirar del molde, reproduciendo así la forma del original.

Los materiales de vaciado pueden diferenciarse en:

a) Materiales originales, que son justamente las mismas materias de las cuales están hechos sus respectivos originales y

b) Materias simuladoras, que son todas aquellas que no siendo del mismo del original, aparentan serlo.

Entre los primeros tenemos las arcillas y los metales, los cuales a partir del molde pueden reproducir el original, aunque por diverso procedimiento. Normalmente con una reducción de tamaño entre un 6 a un $8 \%$, debido a la contracción de secado, cochura y enfriamiento.

Entre los simuladores tenemos los aglomerantes (yeso, cales y cemento) y las resinas duras (expoxídicas y polyesteres) todos ellos con sus respectivas cargas inertes, aditivos, colorantes y pátinas.

Como carga, sirve cualquier sustancia que no afecte el fraguado del material de vaciado. Las arenas, yeso, piedras y ladrillos molidos y cernidos a diferentes mallas, metal pulverizado, etc. y se usan para producir la textura visual, abaratar los costos o mejorar las propiedades del vaciado. Los aglomerantes tienden a imponer su color y textura, por cuanto son opacos y rodean el grano de la carga; en cambio, las resinas, por ser éstas transparentes aunque lo rodeen, dejan traslucir las características de la carga.

Los aditivos son sustancias que hacen variar las propiedades del material usado según sea reque- rido por el procedimiento. Estos son acelerantes, retardadores de fraguado, plastificantes, expansivos, etc.

Colorantes para los aglomerantes son todos aquellos que sirven para la pintura al fresco, por lo general óxidos, los cuales no varían su color por la reacción de fraguado y se diluyen en agua.

Para las resinas sirven, en cambio, los pigmentos al aceite, ya sea en polvo o diluidos ya, como ser óleos o tintas litográficas, pero en pequeña proporción, mezclándolos antes en la resina, ya que debe éste endurecer por fraguado y no por secado como los colores al óleo.

Las pátinas son procedimientos posteriores al fraguado que tienden a avivar los colores que pueden haber palidecido al secar, dar las calidades, brillos, matices o precisar más el color logrado o las transparencias.

La técnica que se use tanto para la confección del molde como para el vaciado estará de acuerdo a las características de la pieza original, considerando además el material que se utilizará para la copia, observando previamente la forma en que se solucionará cada problema.

Los moldes pueden ser:

Rígidos molde perdido molde a piezas

Flexibles

Mixtos

El vaciado puede hacerse a molde abierto (cerrando por presión) o a molde cerrado (a la colada o por inyección).

El enfoque que hace la persona que realiza reproducciones es fundamentalmente distinto al que debió tener la persona que fabricó el original. Este último eligió un material y realizó en él una forma, en cambio para el primero la forma está dada (en el molde) y lo que debe lograr son las características visuales del material hasta el punto en que el especialista no los distingue a simple vista, debiendo observarlos detenidamente para identificar la pieza original, pudiendo así reconocerse en la réplica, no sólo el objeto sino la materia de la cual se fabricó. 